\title{
VII. On a new method of training fruit trees
}

\section{Thos. Andrew Knight Esq. F.R.S.}

To cite this article: Thos. Andrew Knight Esq. F.R.S. (1809) VII. On a new method of training fruit trees, Philosophical Magazine Series 1, 33:129, 35-38, DOI: 10.1080/14786440908562818

To link to this article: http://dx.doi.org/10.1080/14786440908562818

$$
\text { 册 Published online: } 18 \text { May } 2009 .
$$

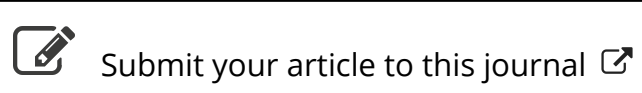

\footnotetext{
山 Article views: 2
}

Q View related articles $\sqsubset$ 
the process of nature; in both eases a stagnation of the true sap is obtained in the fruiting branches, and the redundant nutriment then passes into the fruit.

I have sometimes found that after the circle of bark has been removed, a small portion of the inner bark has adhered to the allurnum: it is of the utmost importance to remove this, though ever so small, otherwise in a very short space of time, the communication is again established with the root, and little or no effect produced. Therefore in about ten days after the first operation has been performed, I generally look at the part from whence the bark was removed, and separate any small portion, which may have escaped the knife the first time.

I am, sir, your obedient servant,

Pitnaston, Worcestershire,

JoHN WILLIAMS.

April 20, 1808.

VII. On a new Method of training Fruit Trees. By Thos. Andrew Knight, Esq., F.R.S., E̊c.**

$F_{\text {rom the result of experiments I have made to ascertain }}$ the influence of gravitation on the descending sap of trees, and the cause of the descent of the radicle, and ascent of the expanding plumule of germinating seerls $\uparrow$, I have been induced to believe that none of the fcrms, in which fruit trees are generally trained, are those best calculated to promote an equal distribution of the circulating fluids; by which alone permanent health and vigour, and power to afford a succession of abundant crops, can be given. I have therefore been lea to try a method of training which is, I believe, different from any that has been practised; and as the success of this method has fully answered every expectation I had formed, I have thought a concise account of it might not be unacceptable to the Horticultural Society. I confine my account to the peach tree, though, with a little variation, the method of training and pruning, that I re-

* From Transactions of the Horticultural Society, vol. $\mathbf{i}$.

+ Philoseplical Transactions, 1806 and 1807.

C 2 commend, 
commend, is applicable, even with superior advantages, to the cherry, plum, and pear tree; and I must observe, that when trees are by any means deprived of the motion, which their branches naturally receive from winds, the forms in which they are trained, operate more powerfully on their permanent bealth and vigour, than is generally imagined.

$\mathrm{My}$ peach trees, which were plants of one year old only, were headed down, as usual, early in the spring, and two shoots only were trained from each stem in opposite directions, and in an elevation of about five degrees; and when the two shoots did not grow with equal luxuriance, I depressed the strongest, or gave a greater elevation to the weakest, by which means both wcre made to acquire and to preserve an equal degree of vigour. These shoots, receiving the whole sap of the plants, grew with much luxuriance, and in the course of the summer each attained about the length of four feet. Many lateral shoots were of course emitted from the young luxuriant branches; but these were pinched off at the first or second leaf; and were in the succeeding winter wholly destroyed; when the plants, after being pruned, appeared as represented in Plate II. Fig. 1. This form, I shall here observe, might with much advantage be given to trees whilst in the nursery; and perhaps it is the only form which can be given, without subsequent injury to the tree : it is also a form that can be given, with very little trouble or expense to the nurseryman.

In the succeeding season as many branches were suffered to spring from each plant as could be trained conveniently, without shading each other; and by selecting the strongest and earliest buds towards the points of the year old branches, and the weakest and latesl near their bases, I was enabled to give to each annual shoot nearly an equal degree of vigour; and the plants appeared in the autumn of the second year nearly as represented in Fig. 2. The experienced gardener will here observe, that I exposed a greater surface of leaf to the light, without placing any of the leaves so as to shade others, than can probably be done in any other mode of training; and in consequence of this arrangement, the growth of the trees was so great, that at two years old some 


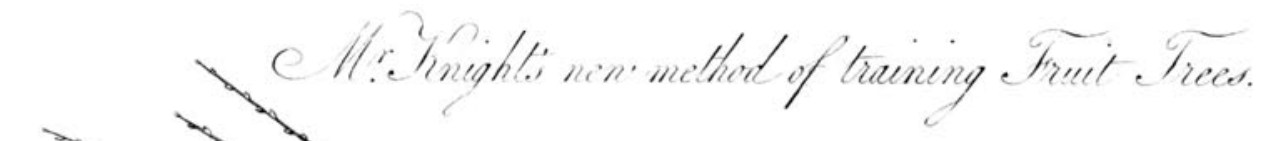

Thil.Mog.Vol.XXXIIIFL

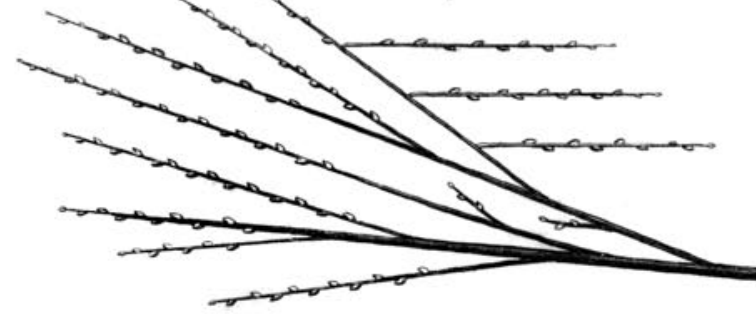

Fig. 3.

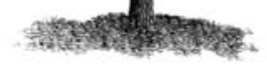

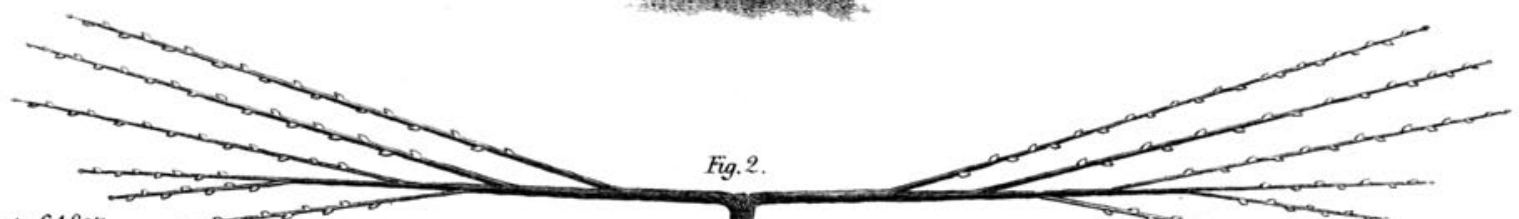

Comet of $180 \%$.
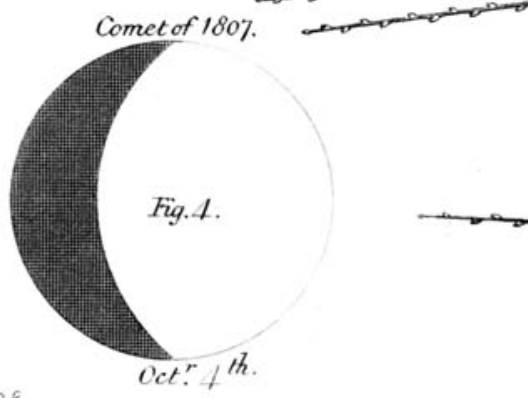

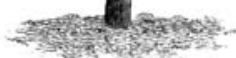
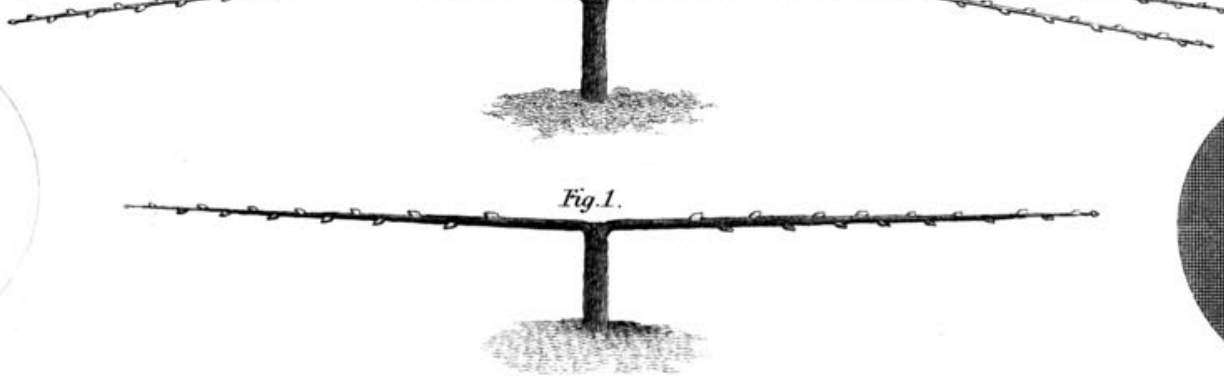

s.Pumes.

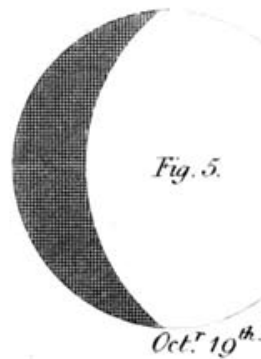


of them were fifteen feet wide; and the young wood in every part acquired the most perfect maturity. In the winter, the shoots of the last season were alternately shortened, and lefi their whole length, and they were then prepared to afford a most abundant and regular blossom in the succeeding spring.

In the autumn of the third year the trees were nearly as represented in Fig. 3, the central part of each being formed of very fine bearing wood; and the size and general health of the trees afford evidence of a more regular distribution of the sap, than I have wituessed in any other mode of training.

In the preceding method of treating peach trees very little use was made of the knife during winter; and I must remark that the necessity of winter pruning should generally be avoided as much as possible; for by laying in a much larger quantity of wood in the summer and autumn than can be wanted in the succeeding year, the gardener gains no other advantage than that of having a "great choice of fine bearing wood to fill his walls," and I do not see any advantage in his having much more than he wants; on the contrary, the health of the trce always suffers by too much use of the knife through successive seasons.

To enter into the detail of pruning, in the manner in which I think it might be done with most advantage, would of necessity lead me much beyond the intended limits of my present communication; but I shall take this opportunity of offering a few observations on the proper treatment of luxuriant shoots of the peach tree; the origin and office of which, as well as the right mode of pruning them, are not at all understood either by the writers on gardening of this country, or the Continent.

I have shown in the Philosophical Transactions of 1805, that the alburnum or sap wood of oak trees loses a considerable part of its weight during the period in which its leaves are formed in the spring; and that any portion of the alburnum affords less extractive matter after the leaves have been formed than previously. I have also shown that the aqueous fluid which ascends in the spring in the birch and 
sycamore becomes specificaily heavier as it ascends towards the buds; which, I think, affords sufficient evidence that the alburum of trees becomes during winter a reservoir of the sap or blood of the tree, as the bulb of the hyacinth, tulip, and the tuber of the potatoe, certainly do of the sap or blood of those plants. Now a wall-tree, from the advantageous position of its leaves relative to the light, probably generates much more sap, comparatively with the number of its buds, than a stanlard tree of the same size; and when it attempts to employ its reserved sap in the spring, the gardener is compelled to destroy (and frequently does so too soon and too abruptly) a very large portion of the small succulent shoots emitted, and the aphis too often prevents the growth of those which remain. The sap in consequence stagnates, and appears often to choke the passages through the small branches; which in consequence become incurably unhealthy, and stunted in their growth : and nature then finds means of employing the accumulated sap, which, if retained, would generate the morbid exudation, gum, in the production of luxuriant shoots. These shoots, our gardeners, from Langley to Forsyth, have directed to be shortened in summer, or cut out in the succeeding spring; but I have found great advantages in leaving them wholly unshortened; when they have uniformly produced the finest possible bearing wood for the succeeding year; and so far is this practice from having a tendency to render naked the lower or internal parts of the tree, whence those branches spring, that the strongest shoots they afford invariably issue from the buds near their bases. I have also found that the laterals that spring from these luxuriant shoots, if stopped at the first leaf, often afford very strong blossoms and fine fruit in the succeeding scason. Whenever therefore space can be found to trais in a luxuriant shoot, I think it should rarely or never be cither cut out, or shortened: it should, however, never be trained perpendicularly, where that can be avoided. 